\title{
Extraction and Spectrophotometric Assay of Yttrium (III) with TOPO, Application to Water Samples and Alloys
}

\author{
Salim Ali Mohammad, Samiea Yaseen Sharaf Zeebaree* \\ Department of Chemistry, College of Science, Mosul University, Mosul, Iraq \\ Email address: \\ Salimsalih813@yahoo.com (S. A. Mohammad), Samie.yasin@dpu.edu.krd (S. Y.Zeebaree) \\ ${ }^{*}$ Corresponding author
}

\section{To cite this article:}

Salim Ali Mohammad, Samiea Yaseen Sharaf Zeebaree. Extraction and Spectrophotometric Assay of Yttrium (III) with TOPO Application to Water Samples and Alloys. Science Journal of Chemistry. Vol. 5, No. 6, 2017, pp. 80-86. doi: 10.11648/j.sjc.20170506.12

Received: October 18, 2017; Accepted: November 6, 2017; Published: November 29, 2017

\begin{abstract}
An easy, accurate, selective and sensitive method for extraction and spectrophotometric determination of yttrium (III) in aqueous solution has been determined. The procedure is based on the extract of yttrium (III) with Trioctylphosphine oxide (TOPO) reagent from the aqueous medium followed reaction of extracted yttrium (III) in organic layer with alizarin red $\mathrm{s}$ (ARS) reagent at $\mathrm{pH} 4.9$ to form a red carmine complex which has maximum absorption at 519 nm. Beer's law is obeyed over the concentration range 10-260 $\mu \mathrm{g}$ yttrium (III) $/ 10 \mathrm{ml}$, (i. e., 1-26 ppm) with a determination coefficient of (0.991) and molar absorptivity of $0.53 \times 10^{4} 1 . \mathrm{mol}^{-1} . \mathrm{cm}^{-1}$. The recoveries are obtained in the range of $98.7-100.01 \%$ and a relative standard deviation is better than $\pm 2.33 \%$. The method has been successfully applied to the determination of yttrium (III) in natural waters and magnesium alloys.
\end{abstract}

Keywords: Yttrium (III), Extraction, TOPO, Spectrophotometric, Alloys

\section{Introduction}

Yttrium is an important member of rare-earth family. It is more abundant than the heavy lanthanides, resembles them in Properties, and occurs with them in nature. Yttrium is never found in nature as the free element. It is found in the three main minerals supplying lanthanides, xenotime, monazite and bastnaesite. Yttrium has silvery-metallic luster and spontaneously igniting in air [1]. In many neutral phosphorus extractant TBP is the earliest applied in rare earth extraction separation [2]. A selective method is presented the solvent extraction of yittrium (III) from salicylate media by using triphenylphosphine oxide [3]. TOPO has been widely used for solvent extraction separation and distribution ratio for most element in the system 5\% TOPO $-\mathrm{HCl}$ have been determined in the rang $1-12 \mathrm{~N} \mathrm{HCl}$ [4]. Solvent extraction of yittrium (III) and trivalent metal ions in weakly acidified 1 mol dm${ }^{3-} \mathrm{NaClO}_{4}$ solution with trioctylphosphine oxide in hexane was studied [5]. A batch solvent extraction process has been developed for the specific purpose of separating $\mathrm{Y}^{91}$ and $\mathrm{Ce}^{144}$ from the gross rare earth fission products fraction. It involves the extraction of these two elements into di (2ethylhexy1)- phosphoric acid (D2EHPA) in Amsco [6]. The extraction behavior of lanthanides and yttrium using CYANIX925 (mixture of branched chain alkylated phosphine oxide in n-heptane from nitrate medium has been studied [7]. Extraction behavior of some tervalent lanthanides from acidic media like $\mathrm{HCl}, \mathrm{H}_{2} \mathrm{SO}_{4}, \mathrm{HNO}_{3}$ and $\mathrm{H}_{3} \mathrm{PO}_{4}$ in a toluene solution of cyanix 923 have been studied [8]. A new kind of hydrophobic ionic liquids [1-alkyl-3-(1-carboxylpropyl)im] [PF6] has been synthesized and their extraction properties for $\mathrm{Y}$ (III) in the nitric acid medium was also investigated [9].

\section{Experimental}

\subsection{Apparatus and Reagents}

Spectral and absorbance measurements are executed using JASCO V-630 double beam UV-Visible spectrophotometer (Japan) with $1-\mathrm{cm}$ quartz cells. The $\mathrm{pH}$ measurements are carried out using HANNA instruments pH 211.

All chemical used are of the highest purity available.

Standard Y (III) solution $(100 \mu \mathrm{g} / \mathrm{ml})$. It was prepared by dissolving $0.341 \mathrm{~g}$ of yttrium chloride hexahydrate (Fluka) in $100 \mathrm{ml}$ distilled water using a volumetric flask.

Dilute $Y$ (III) solution It is prepared by diluting the 
standard solution with the necessary volume of water.

Alizarin red $S$ reagent solution $\left(2 \times 10^{-3} \mathrm{M}\right)$. This solution is prepared by dissolving $0.0342 \mathrm{~g}$ of ARS reagent (Fluka) in 50 $\mathrm{ml}$ distilled water using a volumetric flask and then is transferred to a dark bottle. This solution is stable for at least one week.

TOPO reagent solution $2 \%$ is prepared by dissolving $2 \mathrm{gm}$ of TOPO in $100 \mathrm{ml}$ chloroform.

Sodium salicylate $0.5 \mathrm{M}$ solution is prepared by dissolving $8.005 \mathrm{gm}$ of sodium salicylate salt in $100 \mathrm{ml}$ distilled water using volumetric flask.

Composite mixture solution have prepared by dissolving $1.5 \mathrm{gm}$ of ascorbic acid and $0.02 \mathrm{gm}$ of sodium florid in 50 $\mathrm{ml}$ of distilled water and the mixture solution should be used immediately.

Buffer solution (pH4.9). This solution is prepared by mixing $11 \mathrm{ml}$ of $0.1 \mathrm{M}$ formic acid with $10.5 \mathrm{ml}$ of $0.1 \mathrm{M}$ sodium hydroxide and the volume is completed to $100 \mathrm{ml}$ with distilled water [10].

\subsection{Preliminary Study}

\subsubsection{Effect of Ethanol Quantity}

In order to develop the complex color produced between yttrium (III) and ARS reagent in the organic layer it should be form a homogeneous solution that is accomplished when addition of aqueous solution (contain ARS) to the extracted organic layer which contain complex of (Y-TOPO) dissolved in toluene, however, the final mixture of reaction must be diluted as less as possible by addition of ethanol instead of water, the effect of added (ethanol 96\% ) to the final mixture have been studied establishing that mixing $2 \mathrm{ml}$ of toluene with $3 \mathrm{ml}$ of water followed completing the volume with ethanol to mark of volumetric flask gave a homogeneous solution with high solubility could be depended at adjusting the optimum condition of procedure.

\subsubsection{Recommended Procedure}

A $2.5 \mathrm{ml}$ of $0.5 \mathrm{M}$ of sodium salicylate solution has been added to the $50 \mathrm{ml}$ separatory funnel containing $200 \mu \mathrm{g}$ of yttrium (III), then the volume of aqueous layer is completed to the $25 \mathrm{ml}$ with distilled water, after that a $5 \mathrm{ml}$ of $2 \%$ of TOPO dissolved in toluene must be added with shaking the separatory funnel within 1 minute, the organic layer was separated and $1 \mathrm{ml}$ (contain $40 \mathrm{Mg}$ of $\mathrm{Y}^{3+}$ ) was taken and transferred into $10 \mathrm{ml}$ calibrated flasks with addition $2 \mathrm{ml}$ of $1 \times 10^{-3} \mathrm{M}$ ARS reagent and $1 \mathrm{ml}$ of buffer solution $\mathrm{pH} 4.7$, The solutions are mixed and completed to the mark with ethanol. The absorbance of coloured solution is measured at $523 \mathrm{~nm}$ against the reagent blank solution.

Recommended procedure for the extraction of $\mathrm{Y}$ (III) in natural waters

After filtering the sample, aliquots of not more than $5 \mathrm{ml}$ are taken, and the above procedure described was followed.

\section{Results and Discussion}

The spectrophotometric properties of the extracted product as well as the different parameters affecting the extraction process and colour development of the complex and its stability are studied and optimized. For the following experiments, $1 \mathrm{ml}$ of organic separated layer is taken in a final volume of $10 \mathrm{ml}$.

\subsection{Effect of $\mathrm{pH}$}

In order to detect the ideal $\mathrm{pH}$ of extraction process The addition effect of acid and base in aqueous layer was studied by monitor the absorption of Y (III)-ARS complex after extraction process. The results indicated that the optimum $\mathrm{pH}$ range for aqueous layer was found to be $3.95-6.22$ at which the colour intensity has a Constance maximum absorption at $523 \mathrm{~nm}$ (Figure 1). pH 4.8 is considered the optimum because of the high extraction and good colour contrast.

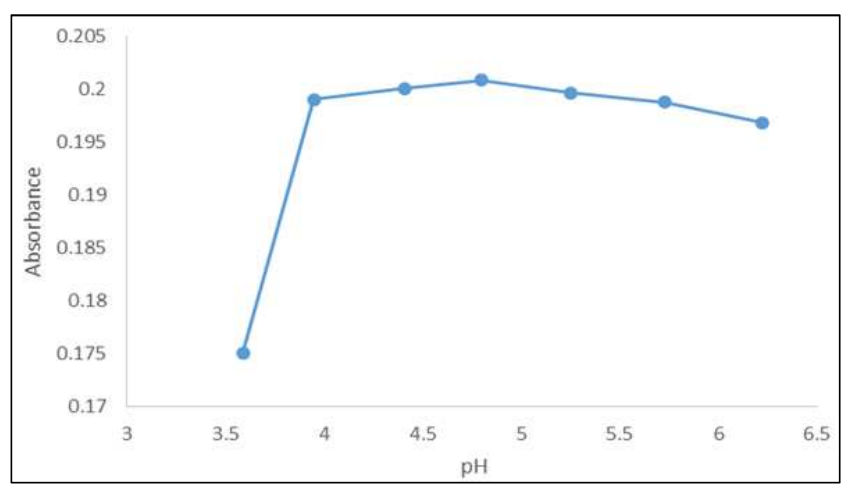

Figure 1. Effect of $p H$ on absorbance.

Therefore, the experimental data of this investigation indicated that $1.5 \mathrm{ml}$ of $0.01 \mathrm{HCl}$ solution lead to optimum $\mathrm{pH}$, therefore it has been selected for the subsequent experiments.

\subsection{Effect of Sodium Salicylate Concentration}

The previous studies point out to the composition of extracted specious as $\mathrm{Y}(\mathrm{Hsal})_{3} .2 \mathrm{TPPO}$ and favouring the extraction by adduct formation. The bis adduct $\mathrm{Y}$ $(\mathrm{Hsal})_{3} .2 \mathrm{TPPO}$ is presumably more hydrophobic than the parent complex $\mathrm{Y}(\mathrm{Hsal})_{3}$, thus favouring its extraction into an organic phase [11].

Any way the effect of sodium salicylate concentration on the extraction of yttrium by TOPO was studied by addition various quantity of it showing that $3 \mathrm{ml}$ of $0.5 \mathrm{M}$ of sodium salicylate gave the better extraction.

Table 1. Effect of sodium salicylate concentration.

\begin{tabular}{ll}
\hline ml of Sodium salicylate $(\mathbf{0 . 5} \mathbf{~ M})$ & Absorbance \\
\hline 1 & 0.1728 \\
1.5 & 0.1886 \\
2 & 0.2002 \\
2.5 & 0.2005 \\
3 & 0.2439 \\
3.5 & 0.2300 \\
4 & 0.2310 \\
4.5 & 0.2290 \\
\hline
\end{tabular}

\subsection{Effect of Organic Solvent}

Influence of variety organic solvent employed to prepare 
TOPO solution has been studied to identify the better efficiency extraction process, a lot of solvents classes was experienced such as xylene, chloroform, cyclohexane, tetrachlorocarbon and toluene, the results indicates that dissolving of TOPO in chloroform solvent gave much more extracted yttrium than another solvents by measuring the absorptivity of extracted species. So it has been selected for the subsequent experiments.

Table 2. Effect of organic solvent.

\begin{tabular}{lll}
\hline Type of solvent & Absorbance & $\boldsymbol{\Lambda}_{\max }$ \\
\hline Cyclohexane & 0.1132 & 520 \\
Chloroform & 0.3021 & 519 \\
$\mathrm{CCl}_{4}$ & 0.2398 & 521 \\
Xylene & 0.1708 & 515 \\
Toluene & 0.2426 & 523 \\
\hline
\end{tabular}

\subsection{Effect of Masking Agent}

In order to enhance the selectivity the effect of common masking agents $\mathrm{NaF}$ and ascorbic acid has been investigated. The experimental data showed that the masking agents used was not effect on the absorbance of the extracted yttrium.

Table 3. Effect of masking agent.

\begin{tabular}{ll}
\hline ml of 3\% ascorbic acid & Absorbance at $\boldsymbol{\lambda}_{\max } \mathbf{5 1 9} \mathbf{~} \mathbf{~ m}$ \\
\hline 1 & 0.3022 \\
2 & 0.3020 \\
3 & 0.3028 \\
5 & 0.2911 \\
\hline
\end{tabular}

During the addition of ascorbic acid it's showing decreasing in $\mathrm{pH}$ of aqueous phase so the $\mathrm{pH}$ should be adjusted by addition a portion of $0.01 \mathrm{M} \mathrm{NaOH}$.

Also the table below showing the effect of $\mathrm{NaF}$ addition

Table 4. Effect of masking agent.

\begin{tabular}{|c|c|}
\hline ml of $0.01 \mathrm{M} \mathrm{NaF}$ & Absorbance \\
\hline 0.5 & 0.3019 \\
\hline 1 & 0.3001 \\
\hline 1.5 & 0.2793 \\
\hline 2 & 0.2716 \\
\hline 2.5 & 0.2623 \\
\hline
\end{tabular}

\subsection{Effect of Composite Mixture Solution}

A composite mixture of $\mathrm{NaF}$ and ascorbic acid was prepared and experienced to investigate their effect on the extraction process, the results indicate that there is no effect of this mixture solution on extraction of yttrium.

Table 5. Effect of composite mixture.

\begin{tabular}{ll}
\hline ml of composite mixture solution (CMS) & Absorbance \\
\hline 0.5 & 0.3011 \\
1 & 0.3021 \\
1.5 & 0.3010 \\
2 & 0.3019 \\
2.5 & 0.2828 \\
3 & 0.2308 \\
\hline
\end{tabular}

\subsection{Effect of TOPO Concentration}

The influence of various concentration of TOPO reagent $(1 \%-3 \%)$ on the efficiency of yttrium extraction have been studied. The table below show that the $5 \mathrm{ml}$ of $2 \%$ show better absorbance therefor it's collected in the next experience.

Table 6. Effect of TOPO concentration.

\begin{tabular}{ll}
\hline Concentration of TOPO (\%) & Absorbance \\
\hline 1.0 & 0.1561 \\
1.5 & 0.1688 \\
2.0 & 0.3014 \\
2.5 & 0.3009 \\
3.0 & 0.3012 \\
\hline
\end{tabular}

\subsection{Effect of Volume Ratio}

to obtain the superior extraction from the aqueous phase, the volume ratio of organic layer to aqueous layer have been investigated by changing the aqueous layer volume (15-30 $\mathrm{ml}$ ) while remaining the organic layer constant, the study demonstrate that the ratio ( $\mathrm{Va} / \mathrm{Vo}$ ) 5:1 gave the preferable extraction as the table showing.

Table 7. Effect of volume ratio.

\begin{tabular}{llll}
\hline ml of aqueous phase (Va) & ml of organic phase (Vo) & Va / Vo ratio & Absorbance \\
\hline 15 & 5 & $3: 1$ & 0.2635 \\
20 & 5 & $4: 1$ & 0.2911 \\
25 & 5 & $5: 1$ & 0.3098 \\
30 & 5 & $6: 1$ & 0.2460 \\
\hline
\end{tabular}

\subsection{Effect Time of Shaking}

A several time periods $(0.5-10)$ minutes was studied to identify the best shaking time of mixture reaction in separatory funnel and showed that the 1 minute is suitable time for shaking to own the best extraction.

Table 8. Effect time of shaking.

\begin{tabular}{lllllll}
\hline Time of shaking (min.) & $\mathbf{0 . 5}$ & $\mathbf{1 . 0}$ & $\mathbf{1 . 5}$ & $\mathbf{2 . 0}$ & $\mathbf{3 . 0}$ & $\mathbf{5 . 0}$ \\
\hline Absorbance & 0.2878 & 0.3099 & 0.3057 & 0.3085 & 0.3006 & 0.3010 \\
\hline
\end{tabular}




\subsection{Effect of pH on the Extraction Process}

After adjusting the optimum condition the efficiency of extraction was studied one more time by addition of acid and base to the aqueous phase, it have showed that efficiency of extraction was reached to $99.2 \%$ while the $\mathrm{pH}$ of aqueous layer is 4.88 .

Table 9. Effect of $\mathrm{pH}$ on the extraction process.

\begin{tabular}{lll}
\hline (ml of HCl solution $\mathbf{0 . 0 1 M})$ & pH of the aq. Layer & Absorbance \\
\hline 0 & 4.32 & 0.3001 \\
0.5 & 3.83 & 0.2922 \\
1 & 3.38 & 0.2612 \\
$\mathrm{ml}$ of $\mathrm{NaOH}$ solution $(0.01 \mathrm{M})$ & pH of the aq. Layer & Absorbance \\
0.5 & 4.54 & 0.2998 \\
1 & 4.88 & $0.3101 *$ \\
1.5 & 5.25 & 0.2911 \\
2 & 5.69 & 0.2509 \\
\hline
\end{tabular}

* $\mathrm{A}=0.3106$ without extraction, $\left[\mathrm{Y}^{3+}\right]=40 \mu \mathrm{g}, \mathrm{D}=620.2, \mathrm{E} \%=99.2$, Vaq. $=25 \mathrm{ml}$, Vorg. $=5 \mathrm{ml}$.

\subsection{Effect of pH on the Complex Formed Between $\mathrm{Y}^{3+}$ and $A R S$}

The absorption value of Y-ARS complex was experienced by measuring the $\mathrm{pH}$ of mixture during addition diluted solution of acid and base. The table below show that the highest value of complex absorption was at the $\mathrm{pH}$ 4.9.

Table 10. Effect of $p H$ on the complex of $Y$-ARS.

\begin{tabular}{lll}
\hline ml of 0.01M HCl solution & $\mathbf{p H}$ of final solution & Absorbance \\
\hline 0.0 & 4.80 & 0.3069 \\
0.5 & 4.41 & 0.2902 \\
1.0 & 3.95 & 0.2711 \\
1.2 & 3.44 & 0.2131 \\
$\mathrm{ml}$ of $0.01 \mathrm{M} \mathrm{NaOH}$ solution & $\mathrm{pH}$ of final solution & Absorbance \\
0.2 & 4.90 & 0.3112 \\
0.3 & 5.07 & 0.3101 \\
0.4 & 5.22 & 0.2714 \\
\hline
\end{tabular}

In order to protect the $\mathrm{pH}$ changing of complex mixture the buffer solution have been prepared (formic acid $-\mathrm{NaOH}$ ) and determined the suitable volume by addition a various quantity of buffer solution and show that $1 \mathrm{ml}$ of buffer solution could maintain the $\mathrm{pH}$ value.

Table 11. Effect of buffer solution.

\begin{tabular}{lll}
\hline \multirow{2}{*}{ ml of buffer solution (pH4.9) } & Absorbance & \\
\cline { 2 - 3 } & Sample solution & Blank solution \\
\hline 0.5 & 0.3011 & 0.0136 \\
0.7 & 0.3142 & 0.0144 \\
1 & 0.3145 & 0.0141 \\
1.2 & 0.3100 & 0.0170 \\
1.5 & 0.2956 & 0.0200 \\
\hline
\end{tabular}

\subsection{Effect of ARS Reagent Amount}

The effect of different amounts $(0.3-1.8 \mathrm{ml})$ of $2 \times 10^{-3} \mathrm{M}$ ARS on the absorbance of the resulting complex Y (III)-ARS have been studied. The results in Table show that $1.3 \mathrm{ml}$ of $2 \times 10^{-3}$ M ARS solution show better absorbance at $519 \mathrm{~nm}$ therefore it is recommended for the subsequent experiments.

Table 12. Effect of ARS reagent.

\begin{tabular}{ll}
\hline $\mathbf{m l ~ o f ~} \mathbf{2} \times \mathbf{1 0}^{-3} \mathbf{M}$ ARS reagent & Absorbance \\
\hline 0.3 & 0.2821 \\
0.5 & 0.3412 \\
0.8 & 0.3663 \\
1 & 0.3774 \\
1.3 & 0.3801 \\
1.5 & 0.3751 \\
1.8 & 0.3556 \\
\hline
\end{tabular}

\subsection{Effect of CTAB Surfactant}

To know the influence of surfactant solution on the absorption value of complex formed the series of test have been done and show that there is a negative effect was achieved while addition of CTAB surfactant so it have been excluded.

Table 13. Effect of surfactant.

\begin{tabular}{ll}
\hline ml of CTAB solution $\left(\mathbf{1} \times \mathbf{1 0}^{-\mathbf{2}} \mathbf{M}\right)$ & Absorbance \\
\hline 0.3 & 0.3638 \\
0.5 & 0.3771 \\
0.8 & Turbid \\
1 & Turbid \\
1.5 & Turbid \\
\hline
\end{tabular}

\subsection{Effect of Time on the Stability of Complex}

After adjusting the optimum condition of the color reaction between yttrium (III) and ARS reagent the effect of time on the stability of complex have been studied, its show that the complex is stable for 1 hour.

Table 14. Stability of complex.

\begin{tabular}{llc}
\hline \multirow{2}{*}{ Time (min) } & \multicolumn{2}{l}{ Absorbance / $\boldsymbol{\mu g}$ of Y (III) extracted } \\
\cline { 2 - 3 } & $\mathbf{2 5}$ & $\mathbf{5 0}$ \\
\hline Immediately & 0.1791 & 0.4051 \\
2 & 0.1815 & 0.4063 \\
5 & 0.1853 & 0.4102 \\
10 & 0.1911 & 0.4111 \\
15 & 0.1912 & 0.4113 \\
20 & 0.1912 & 0.4121 \\
25 & 0.1933 & 0.4132 \\
30 & 0.1935 & 0.4165 \\
40 & 0.1983 & 0.4192 \\
50 & 0.1985 & 0.4221 \\
60 & 0.1997 & 0.4275 \\
\hline
\end{tabular}

\subsection{Final Absorption Spectrum}

The final spectrum has been drew after set the optimum condition by transfer $1 \mathrm{ml}$ of extracted yttrium $(40 \mu \mathrm{g})$ to the volumetric flask of $10 \mathrm{ml}$ followed by addition $1.3 \mathrm{ml}$ of (2 $\left.\times 10^{-3} \mathrm{M}\right)$ ARS and $1 \mathrm{ml}$ of buffer solution $(\mathrm{pH}=4.9)$ then the volume was completed with ethanol to the mark to form a red carmine complex which has maximum absorption at $519 \mathrm{~nm}$. 


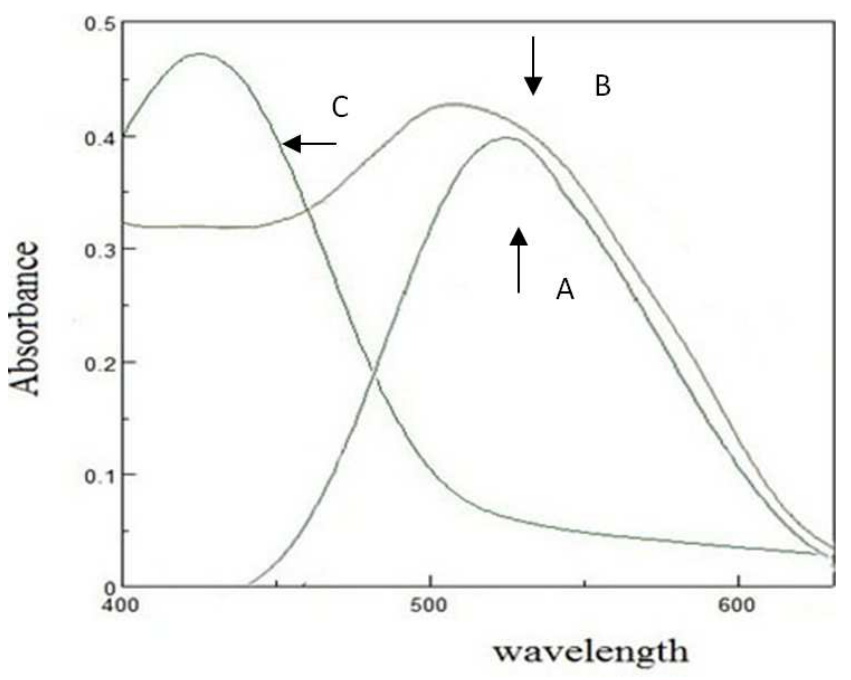

Figure 2. Final absorption spectrum of $40 \mu \mathrm{g} Y^{3+}$.

$\mathrm{A}=\mathrm{Y}^{3+}$ verses Blank.

$\mathrm{B}=\mathrm{Y}^{3+}$ verses $\mathrm{D}$. W.

$\mathrm{C}=$ Blank verses $\mathrm{D} . \mathrm{W}$.

\section{Quantification}

In order to investigate the range in which the colored complex adheres to Beer's law, the absorbance of the complex is measured at $519 \mathrm{~nm}$ after extraction of yttrium and developing the colour by following the suggested procedure for a series of solutions containing increasing amounts of Y (III) (Figure 3).

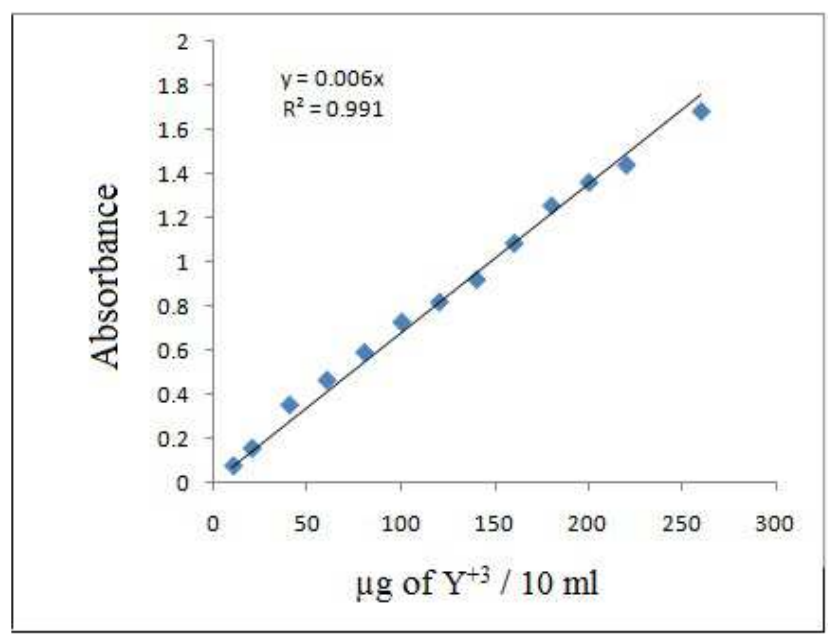

Figure 3. Calibration curve for Y (III) determination.
The Beer's law limits, molar absorptivity, Sandell's sensitivity, (LOD) and (LOQ) values [12] are evaluated and are given in Table 15 which indicates that the method is sensitive. Linearity is represented by the regression equation and the corresponding determination coefficient for $\mathrm{BH}$ determined by the proposed method represents excellent linearity $\left(\mathrm{R}^{2}=0.9954\right)$. The relative standard deviation (RSD) and accuracy (recovery \%) for the analysis of five replicates of each of the three different concentrations of $\mathrm{BH}$ indicates that the method is precise and accurate.

Table 15. Summary of optical characteristics and statistical data for the proposed method.

\begin{tabular}{ll}
\hline Parameter & Values of method \\
\hline Beer's law limits $(\mathrm{ppm})$ & $1-26$ \\
Molar absorptivity $\left(\mathrm{l} \cdot \mathrm{mol}^{-1} \cdot \mathrm{cm}^{-1}\right)$ & $0.53 \times 10^{4}$ \\
Sandell's sensitivity $\left(\mu \mathrm{g} \cdot \mathrm{cm}^{-2}\right)$ & ----- \\
Slope & 0.006 \\
Intercept, $b$ & ---- \\
Determination coefficient & 0.991 \\
Range of recovery $*(\%)$ & $94.73-103.77 \%$ \\
RSD* $(\%)$ & Better than $\pm 2.33 \%$. \\
\hline
\end{tabular}

* Average of five determinations in sea water.

\section{Effect of Foreign Ions}

The effect of various amounts of many foreign ions on the extraction of $\mathrm{Y}$ (III) are examined using the recommended procedure. The results obtained are summarized in Table 16.

Table 16. Individual tolerance limit of foreign ions on the extraction of $40 \mu \mathrm{g}$ $Y(I I I)$.

\begin{tabular}{ll}
\hline Foreign ion added & $\begin{array}{l}\text { Tolerance limit, } \\
\boldsymbol{\mu g}\end{array}$ \\
\hline $\mathrm{Mg}^{2+}, \mathrm{Mo}^{6+}, \mathrm{SO}_{4}^{2-}, \mathrm{Fe}^{3+}$ & 2000 \\
$\mathrm{Al}^{3+}, \mathrm{Ce}^{4+}, \mathrm{Co}^{+2}, \mathrm{Cu}^{+2}, \mathrm{Fe}^{+2}, \mathrm{Ni}^{+2}, \mathrm{Ti}^{+3}, \mathrm{~W}^{+6}, \mathrm{Zn}^{+2}, \mathrm{Zr}^{+4}$ & 1500 \\
$\mathrm{Bi}^{3+}, \mathrm{Th}^{4+}, \mathrm{PO}_{4}^{3-}, \mathrm{La}^{3+}, \mathrm{Sn}^{2+}$ & 200 \\
\hline
\end{tabular}

As shown in Table 16, the largest interfering species are found to be $\mathrm{Bi}^{2+}, \mathrm{La}^{3+}, \mathrm{Th}^{4+}, \mathrm{PO}_{4}{ }^{3-}$ ions.

\section{Application}

\subsection{Determination of Yttrium in Water Samples}

The present method has been applied to determination of $\mathrm{Y}$ (III) at three different concentrations added to appropriate volumes of river and sea waters. The results are compiled in Table 17 and showed that the proposed method is suitable for determining Y (III) with satisfactory recovery.

Table 17. Determination of yttrium in natural waters.

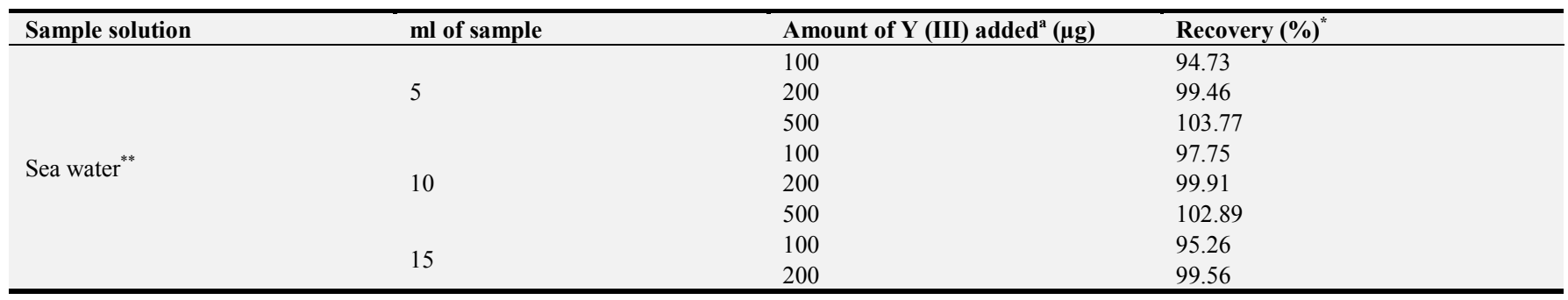




\begin{tabular}{llll}
\hline Sample solution & ml of sample & ${\text { Amount of Y (III) } \text { added }^{\mathbf{a}}(\boldsymbol{\mu} \mathbf{g})}$ & Recovery (\%) $^{\text {* }}$ \\
\hline & & 500 & 99.31 \\
& 5 & 100 & 98.14 \\
& & 200 & 96.91 \\
& & 500 & 102.05 \\
River water (Tigris river) & 10 & 100 & 98.98 \\
& & 200 & 99.11 \\
& \multirow{2}{*}{15} & 500 & 99.89 \\
& 100 & 96.33 \\
& 200 & 103.5 \\
\hline
\end{tabular}

*Average of five determinations a. Amount of Y (III) added to separating funnel.

**Synthetic sea water [13].

\subsection{Determination of Yttrium in Prepared Magnesium Alloys}

Yttrium has been determined in a sample contain a various ions that prepared in lab.

Table 18. Extraction of Yttrium in Synthetic Alloys.

\begin{tabular}{llll}
\hline Sample of synthetic mixture** & Sample composition $(\boldsymbol{\mu g})$ & Amount of $\mathrm{Y}$ (III) found $(\boldsymbol{\mu g})$ & Recovery* $(\%)$ \\
\hline SMI & $\mathrm{Mg}^{2+}(3000), \mathrm{Zr}^{4+}(200), \mathrm{Y}^{3+}(200)$ & 206.02 & 103.01 \\
SMII & $\mathrm{Fe}^{3+}(50), \mathrm{Mg}^{2+}(2000), \mathrm{Y}^{3+}(200), \mathrm{SO}_{4}{ }^{2-}(50)$ & 197.40 & 98.70 \\
\hline
\end{tabular}

*Average of three determinations.

**Magnesium alloys, are used in aircraft and high performance vehicles [14].

\subsection{Comparison of Methods}

Table (19) shows the comparison of spectrophotometric methods for Yttrium (III) determination based on chelating with some organic reagents.

The present method seems to compare favorably with the methods cited in the literature.

Table 19. Comparison of method.

\begin{tabular}{|c|c|c|}
\hline Analytical parameter & Present method & Literature method $^{[14]}$ \\
\hline Reagent & ARS & ARS \\
\hline $\mathrm{pH}$ of colure development & 4.9 & 4.7 \\
\hline$\lambda_{\max }(\mathrm{nm})$ & 519 & 535 \\
\hline Determination coefficient $\left(\mathrm{r}^{2}\right)$ & 0.9910 & - \\
\hline Beers law rang $(\mu \mathrm{g} / \mathrm{ml})$ & $1-26$ & - \\
\hline Molar absorptivity $\left(1 . \mathrm{mol}^{-1} . \mathrm{cm}^{-1}\right)$ & $0.53 \times 10^{4}$ & - \\
\hline Solvent used & Chloroform & Xylene \\
\hline Extraction reagent & TOPO & $N$ - $n$-octylaniline \\
\hline Equilibrium time (min) & 1 & 5 \\
\hline Time of color development & Immediately & Immediately \\
\hline Recovery (\%) & $98.7-100.01$ & $98.5-99.5$ \\
\hline Surfactant & none & None \\
\hline Stripping agent & none & $\mathrm{HCl}$ \\
\hline Application & Determination of Y (III) in natural waters and Magnesium alloys & Determination of Y (III) in synthetic mixtures \\
\hline
\end{tabular}

\section{Conclusion}

A sensitive and selective spectrophotometric method has been developed for the extraction and determination of yttrium in aqueous solution using TOPO as extraction agent and alizarin red $\mathrm{S}$ as chelating agent at $\mathrm{pH} 4.9$. The coloured complex exhibits a molar absorptivity $0.53 \times 10^{4} 1 . \mathrm{mol}^{-1} . \mathrm{cm}^{-1}$ at $519 \mathrm{~nm}$. Beer's law is obeyed over the concentration range 1-26 ppm. The method has been applied successfully to the determination of yttrium (III) natural waters and synthetic alloys.

\section{References}

[1] Osman, A., D., (2006). Ph. D. Thesis, Liquid-Liquid Extraction of Rare Earth Elements from Sulfuric Acid Solutions. Department of Chemistry, University of Leeds. p. 48 .

[2] Li deqian, (2017), A review on yttrium solvent extraction chemistry and separation process, journal of rare earths, 35(2), 107. 
[3] N., G., Bhilare, V., M., Shinde, (1996), Liquid-liquid extraction and separation studies of yttrium, Fresenius J Anal Chem, 354, 122-124.

[4] E., Steinnes, O., R., Birkelund, O., Johansen, (1971), Determination of trace element in biological material by neutron activation and extraction with TOPO, journal of radioanalytical chemistry, 9, 267-272.

[5] M., Yamada, S., Kusakabe, J., Prekopova And T., Sekine, (1996), Solvent Extraction of Seven Trivalent Metal Ions in Aqueous Perchlorate Solutions with Trioctylphosphine Oxide in Hexane and Rapid Extraction of Chromium (III), Analytical science, 12, 405 .

[6] T., A., Butler, E., E., Ketchen, (1961), Solvent Extraction Separation of Cerium and Yttrium from Other Rare Earth Fission Products, Industrial and engineering chemistry, 53(8), 651-654.

[7] W., Li, X., Wang, H., Zhang, S., Meng, D., Li, (2007), Solvent extraction of lanthanides and yttrium from nitrate medium with cyanex 925 in heptane, Chemical technology and biotechnology, 82(4), 376-381.

[8] B., Gupta, P., Malak and A., Deep, (2003), Solvent extraction and separation of tervalent lanthanides and yttrium using cyanix 923, solvent extraction and ion exchange, 21(2), 239258.

[9] W., Wei, L., Yu, X., Aimei, Y., Hualing, C., Hongmin and C., $\mathrm{Ji}$, (2012), Solvent extraction of yttrium by task -specific ionic liquid bearing carboxylic group, Chinese journal of chemical engineering, 20(1), 40-46.

[10] D., D., Perrin, B., Dempsy, 1974. Buffers for $\mathrm{pH}$ and metal Ion Control. Champan and Hall Ltd., London, 132.

[11] International Conference on Harmonization (2005), ICH Harmonized Tripartite Guide-line: Validation of Analytical Procedures Text and Methodology, Q2 (R1), Current Step 4 Version, 11-13.

[12] Henriksen, A., 1965. An Automatic Method for Determining Nitrate and Nitrite in Fresh and Saline Waters, Analyst, 90, 83-88.

[13] https://en.wikipedia.org/wiki/Magnesium_alloy/ (accessed 15 April 2015).

[14] B., N., Kokare, A., M., Mandthare, S., S., Kolekar and M., A., Anuse, N-n-octylaniline as a New reagent for analytical Liqiud-liqiud extraction of yttrium (III) from matrices of various metal ions, Macedonian Journal of Chemistry and Chemical Engineering, (2011), 30 (2) p. 151-162. 